\title{
Bivalve Shells-Unique High-Resolution Archives of the Environmental Past
}

\author{
Lars Beierlein, Gernot Nehrke, Tamara Trofimova and Thomas Brey
}

\begin{abstract}
Understanding the climate of the past is essential for anticipating future climate change. Palaeoclimatic archives are the key to the past, but few marine archives (including tropical corals) combine long recording times (decades to centuries) with high temporal resolution (decadal to intra-annual). In temperate and polar regions carbonate shells can perform the equivalent function as a proxy archive as corals do in the tropics. The bivalve Arctica islandica is a particularly unique bio-archive owing to its wide distribution throughout the North Atlantic and its extreme longevity (up to 500 years). This paper exemplifies how information at intra-annual and decadal scales is derived from $A$. islandica shells and combined into a detailed picture of past conditions. Oxygen isotope analysis $\left(\delta^{18} \mathrm{O}\right)$ provides information on the intra-annual temperature cycle while frequency analysis of shell growth records identifies decadal variability such as a distinct 5-year signal, which might be linked to the North Atlantic Oscillation.
\end{abstract}

Keywords Sclerochronology - Arctica islandica - Frequency analysis - Raman microscopy $\cdot$ Stable oxygen isotopes $\cdot$ Palaeoceanography $\cdot$ Intra-annual $\cdot$ Decadal

\section{Introduction}

Current predictions of future climate change (e.g., IPCC 2013) are based on global circulation models (GCM) to a large extent. Such models incorporate observational and instrumental data of the oceans, continents and atmosphere. Instrumental data are available for the last two centuries at best, but we need climate and

L. Beierlein $(\bowtie) \cdot$ G. Nehrke $\cdot$ T. Brey

Alfred Wegener Institute Helmholtz Centre for Polar and Marine Research,

Bremerhaven, Germany

e-mail: Lars.Beierlein@awi.de

T. Trofimova

Saint Petersburg State University, St. Petersburg, Russia

(C) Springer International Publishing Switzerland 2015

G. Lohmann et al. (eds.), Towards an Interdisciplinary Approach

in Earth System Science, Springer Earth System Sciences,

DOI 10.1007/978-3-319-13865-7_19 
environmental data prior to the instrumental era in order to improve and verify such climate models. Therefore, climate sciences rely on climate archives such as sediment cores and ice cores. Such archives contain "proxies", i.e. physical, chemical or biological properties that correlate to certain environmental parameters and hence allow reconstructions of such parameters at the time of the formation of the archive. The relationship between water temperature and $\delta^{18} \mathrm{O}$ is thought to be the most important relationship between an environmental parameter and its proxy.

Accretionally growing hard parts of aquatic organisms (e.g., corals, fish and squid otoliths, coralline algae, bivalve shells) are being used as climate archives

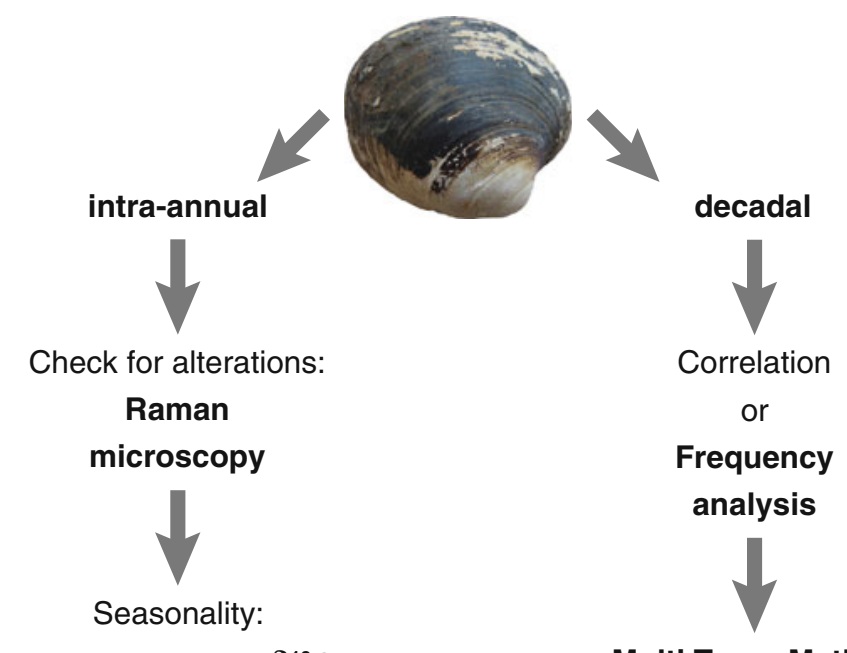

oxygen isotopes $\delta^{18} \mathrm{O}$

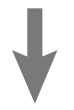

annual cyclicity

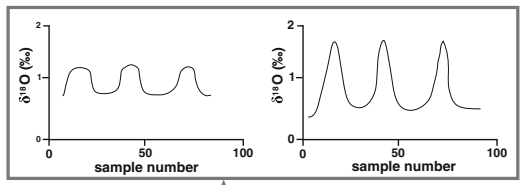

4
Multi Taper Method

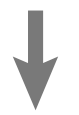

5 -year signal

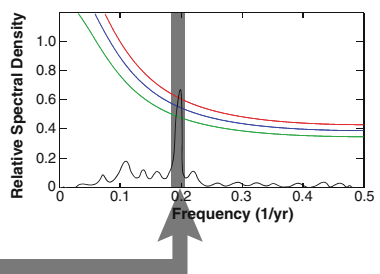

Fig. 1 Flow chart illustrating potential reconstruction techniques on various time-scales for bivalve shells. Geochemical analyses, such as $\delta^{18} \mathrm{O}$ as a proxy for water temperatures, allow reconstructions on an intra-annual level. A test for preservation in fossil specimens-e.g., by using CRM - should be obligatory. The shell of A. islandica can additionally be used for a frequency analysis (e.g., Multi Taper Method) of the annual growth pattern, allowing the identification of decadal variabilities, such as a 5-year quasi-periodic signal 
with increasing frequency, providing environmental information on daily to multicentennial time-scales (Schöne et al. 2005b; Hallmann et al. 2009; Butler et al. 2010). For this purpose, analyses of the anatomical-morphological features of the skeletal hard parts - such as growth patterns and crystal structures - are commonly combined with geochemical analyses (e.g., stable isotopes, trace elements). Due to its wide distribution throughout the North Atlantic (Dahlgren et al. 2000) and its longevity (500 years and more, Butler et al. 2013), the bivalve Arctica islandica represents an exceptional bio-archive for northern temperate regions.

A. islandica forms annual growth rings (increments), which can be measured and used as a calendar (Jones 1980). However, when working with fossil specimens, the state of preservation is an essential aspect to consider prior to any kind of geochemical analysis (e.g., stable oxygen isotopes $\left(\delta^{18} \mathrm{O}\right)$ as a proxy for water temperature and salinity). Confocal Raman microscopy (CRM) is a non-destructive method, which allows a test for diagenetic alteration on the same sample that will later be used for the geochemical measurement.

The annual growth rate of bivalves mainly depends on ambient water temperature and food quality and availability (e.g., Witbaard et al. 1997) which vary on a regional scale, but may be affected by large-scale ocean-atmosphere phenomena, too (Schöne et al. 2003a), like the North Atlantic Oscillation (NAO). The frequency analysis of the growth record of just a single A. islandica shell can identify such decadal signals (several years to decades) in a time window corresponding to the animal's lifetime.

For demonstration purposes we combine the results from modern and fossil shell material to emphasise the unique character of the bio-archive A. islandica. We demonstrate its outstanding potential in terms of intra-annual (stable oxygen isotopes) as well as decadal (frequency analysis) climatic and environmental reconstructions and show how these can be combined to inform our understanding of climate in the past (Fig. 1).

\section{Methods}

\subsection{Shell Origin and Laboratory Work}

We use three A. islandica specimens of different geological age (see Table 1 for details) to demonstrate how sclerochronological analyses at intra-annual and decadal scale fit together. The CRM approach has been applied on Pliocene specimen AI-TjBe-01, which was removed from the biostratigraphically dated Tjörnes Bed formation, Iceland. Specimen AI-EgLo-02 has been found dead in beach deposits at the Lofoten, Norway, and used for the frequency analysis. Further, specimen 
Table 1 Shell information

\begin{tabular}{l|l|l|l|l|l|l|l}
\hline Shell ID & $\begin{array}{l}\text { Length } \\
(\mathrm{mm})\end{array}$ & $\begin{array}{l}\text { Height } \\
(\mathrm{mm})\end{array}$ & $\begin{array}{l}\text { Width } \\
(\mathrm{mm})\end{array}$ & Locality & $\begin{array}{l}\text { Geological } \\
\text { age }\end{array}$ & $\begin{array}{l}\text { Ontogenetic } \\
\text { age (years })\end{array}$ & $\begin{array}{l}\text { Applied } \\
\text { method }\end{array}$ \\
\hline Ai24568 & 86.7 & 82.0 & 23.2 & $\begin{array}{l}\text { Tromso, } \\
\text { Norway }\end{array}$ & Modern & 71 & $\begin{array}{l}\text { Oxygen } \\
\text { isotope } \\
\text { analysis }\end{array}$ \\
\hline AI-EgLo-02 & 53.3 & 46.6 & 14.0 & $\begin{array}{l}\text { Lofoten, } \\
\text { Norway }\end{array}$ & $\begin{array}{l}\text { Found dead, } \\
\text { beach } \\
\text { deposit }\end{array}$ & 45 & $\begin{array}{l}\text { Frequency } \\
\text { analysis }\end{array}$ \\
\hline AI-TjBe-01 & $57.2^{*}$ & 84.0 & $24.4^{*}$ & $\begin{array}{l}\text { Tjörnes, } \\
\text { Iceland }\end{array}$ & Pliocene & $\begin{array}{l}\text { Not } \\
\text { determined }\end{array}$ & $\begin{array}{l}\text { Raman } \\
\text { microscopy }\end{array}$ \\
\hline
\end{tabular}

Information on shell morphology, shell origin, geological and ontogenetic ages as well as applied methods are given. Measurements marked with (*) for specimen AI-TjBe-01 give values for partly fragmented shell portions

Ai24568 has been live-collected in Tromsø, Norway in 2006 and used for the $\delta^{18} \mathrm{O}$ approach.

In the laboratory, all specimens were cleaned using a paintbrush, deionized water and an ultrasonic bath. Afterwards, shells were externally strengthened with an epoxy resin and cut along the line of strongest growth (LSG, Fig. 2). The cut shell sections were glued onto glass slides and ground on sandpaper with varying grain sizes of 15,10 and $5 \mu \mathrm{m}$ respectively.

To improve the visibility of the individual growth increments, the thick-section intended for the frequency analysis (shell ID: AI-EgLo-02) was stained with Mutvei's solution (Schöne et al. 2005a). Digital images were taken under a stereomicroscope (Olympus, SZX12) attached to a CCD camera (Olympus) and
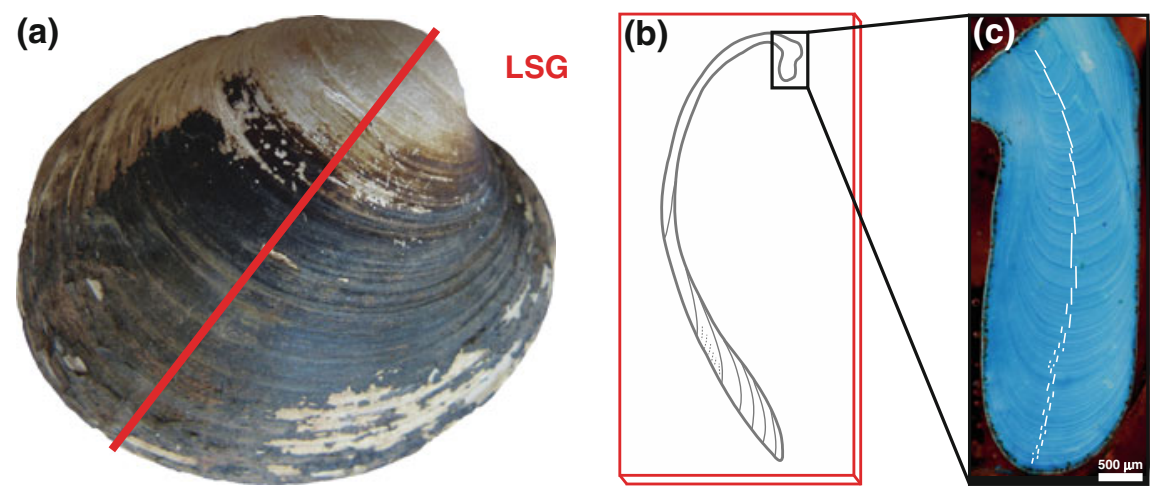

Fig. 2 Cutting axis and location of shell increments in A. islandica. a Right valve of an $A$. islandica specimen with line of strongest growth (LSG, equals cutting axis). b Graphical illustration of an A. islandica thick-section after cutting through the LSG (red). Black box indicates the umbonal area shown in c. c Magnification of the umbonal area, stained in Mutvei's solution and showing annual growth increments. Growth band widths are measured perpendicular to the increments, as indicated by the white lines 
increment width was measured using the image processing software analySIS (Olympus, version 5.1).

\subsection{State of Preservation}

The shells of $A$. islandica consist of aragonite $\left(\mathrm{CaCO}_{3}\right)$, trace elements and organics (e.g., Schöne 2013). After burial and in terms of fossilisation, several factors such as heat and pressure at depth, as well as hydrothermal fluids, can cause alterations in the shell carbonate, e.g., recrystallization from pristine aragonite to the more stable $\mathrm{CaCO}_{3}$ polymorph calcite (e.g., Bathurst 1964). In most cases the recrystallization process involves a dissolution and recrystallization process (neomorphism, e.g., Maliva 1998), which would replace the pristine stable oxygen isotope ratio within the carbonate and erase the associated environmental signal in the shell (e.g., Hendry et al. 1995).

Due to its high spatial resolution of a few hundred nm CRM provides an ideal tool for shell carbonate analysis. For our measurements on Pliocene specimen AI-TjBe-01 we used a WITec alpha $300 \mathrm{R}$ instrument, equipped with a diode laser (excitation wavelength $532 \mathrm{~nm}$ ) and a 20× Zeiss objective. Details on the measurements can be found in Nehrke et al. (2012).

\subsection{Frequency Analysis}

The growth record of shell AI-EgLo-02 was detrended using a cubic spline (JMP software, version 9.0.1 by SAS Institute Inc. 2007), and a standardized growth index (SGI) was calculated following Butler et al. (2010). The subsequent frequency analysis was conducted using kSpectra software (version 3.4 by SpectraWorks) with settings according to Ivany et al. (2011) and applying a Singular Spectrum Analysis (SSA) and the Multi Taper Method (MTM). Furthermore, we used wavelet transformation to examine whether quasi-periodic signals were stationary over time (http://ion.researchsystems.com/IONScript/wavelet/), following Torrence and Compo (1998). Growth records of specimens Ai24568 and AI-TjBe-01 have not been analysed.

\subsection{Stable Oxygen Isotopes $\left(\delta^{18} \mathrm{O}\right)$}

During shell formation, $A$. islandica incorporates oxygen isotopes in equilibrium with the surrounding seawater (Weidman and Jones 1994). Since the incorporation of lighter oxygen isotopes is facilitated during higher temperatures (Grossman and $\mathrm{Ku}$ 1986), the oxygen isotope ratio $\delta^{18} \mathrm{O}$ of most bivalve species provides 
information on water temperatures (e.g., Schöne et al. 2005c) and salinity (e.g., Schöne et al. 2003b) at the moment of shell formation. In general, the modified temperature equation by Dettman et al. (1999) is used for A. islandica, which is based on the empirically determined relationship between temperature and $\delta^{18} \mathrm{O}$ for aragonite by Grossman and $\mathrm{Ku}(1986)$.

Carbonate samples were milled by hand (Dettman and Lohmann 1995) using a $700 \mu \mathrm{m}$ drill bit (Komet/Gebr. Brasseler $\mathrm{GmbH} \&$ Co. KG) mounted onto an industrial high precision drill (Minimo C121, Minitor Co., Ltd.) and attached to a binocular microscope. Measurements were performed on a Thermo Finnigan MAT 253 isotope ratio mass spectrometer and calibrated against a NBS-19 standard with a precision error of $0.08 \%$ for oxygen. Shell-derived water temperatures have been compared to SST measurements reported online (http://www.seatemperature.org/ europe/norway/tromso.htm).

\section{Results}

\subsection{State of Preservation}

From the Raman scan it can be seen that the area of the fossil A. islandica shell (shell ID: AI-TjBe-01) marked in Fig. 3a consisted of both aragonite and calcite. An area scan of $520 \times 500 \mu \mathrm{m}$ (Fig. 3b), partly covering the potentially recrystallized shell portion, indicates the distribution of (pristine) aragonite and (recrystallized) calcite within the shell carbonate. Both polymorphs share carbonate-specific peaks at 155 and $1085 \mathrm{~cm}^{-1}$ in their Raman spectra (Fig. 3c). The aragonite-specific peak at $\sim 206 \mathrm{~cm}^{-1}$ (blue line in Fig. 3c) is shifted towards $\sim 280 \mathrm{~cm}^{-1}$ in (recrystallized) calcite (red line in Fig. 3c).
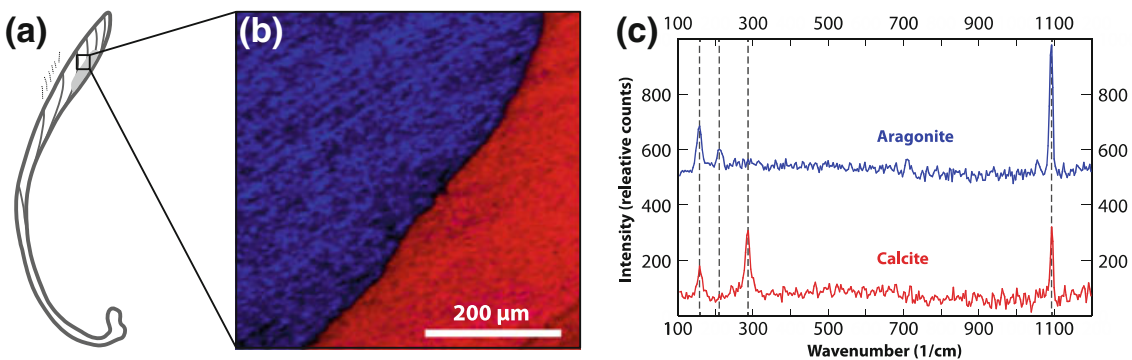

Fig. 3 State of preservation tested by confocal Raman microscopy. a Schematic illustration of a (fossil) A. islandica specimen. Light grey colour exemplary indicates area of potential recrystallization. b Areal CRM scan in specimen AI-TjBe-01 close to the altered shell portion and as indicated in a. Two different materials have been identified. c Raman spectra for two different polymorphs of calcium carbonate explaining colour coding in B. Intensity differences in liberation modes (peaks at $\sim 206 \mathrm{~cm}^{-1}$ for aragonite and $\sim 280 \mathrm{~cm}^{-1}$ for calcite) in single spot Raman spectra identify pristine aragonite (blue) and recrystallized calcite (red) 
Fig. 4 Frequency analysis on A. islandica growth pattern. a Standardized growth index (SGI) giving relative information on positive (above 0) or negative (below 0 ) deviations from average shell growth. b Multi Taper Method (MTM) applied to the SGI shown in a. Red, blue and green lines represent significance levels of 99,95 and $90 \%$, respectively. The significant $(95 \%)$ signal at the frequency of 0.197 (1/year) corresponds to a 5-year signal (combined SSA and MTM analysis). c Wavelet transformation giving information on the stationarity of quasi-periodic signals identified by SSA and MTM. The strength of the 5-year quasi-periodic signal varies over time, being more prominent from ontogenetic year 20 onwards. d Results for the $\delta^{18} \mathrm{O}$ analysis in three ontogenetic years throughout the pronounced phase of the 5 -year signal, as indicated in c. $\delta^{18} \mathrm{O}$ values have been translated into water temperatures according to Dettman et al. (1999) assuming a $\delta^{18} \mathrm{O}_{\text {seawater value }}$ of $0 \%$. Arrows indicate summer peaks and winter troughs (a)

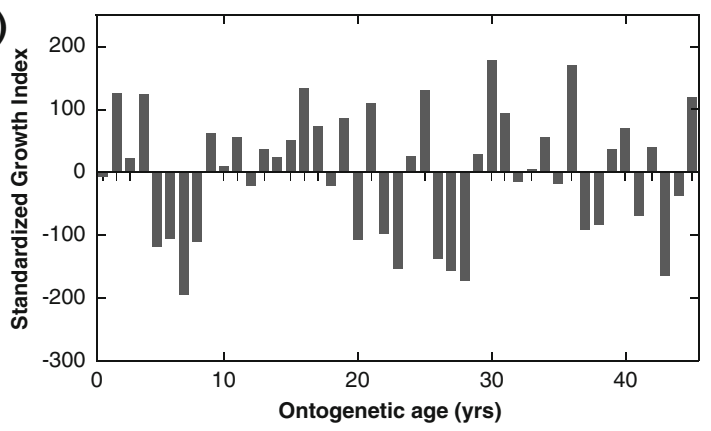

(b)

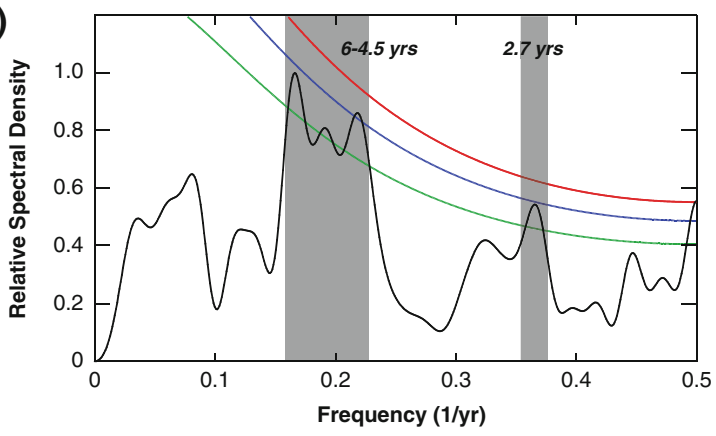

(c)

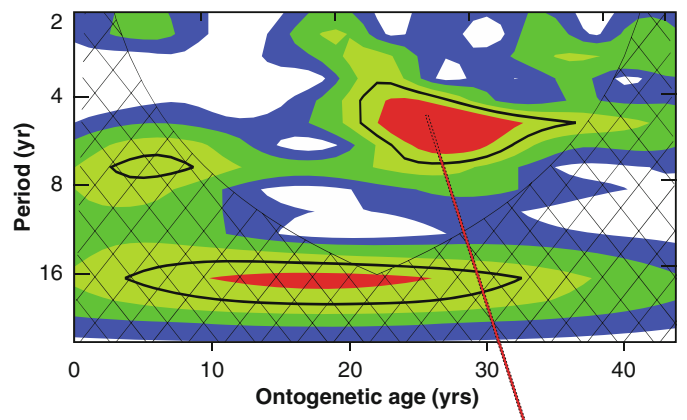

(d)

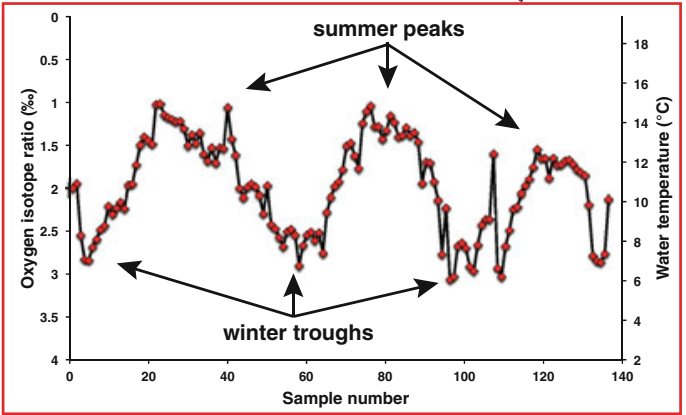




\subsection{Frequency Analysis}

The frequency analysis of the SGI (Fig. 4a) in specimen AI-EgLo-02 indicates a significant (95\% level) 5-year signal (Fig. 4b). Additionally, a signal at 2.7 years was significant at the $90 \%$ level. The wavelet transformation shows the variability of the indicated signals over time. Strength of the 5-year signal varies distinctly over time and is most prominent between ontogenetic years 20 and 30 (Fig. 4c).

\subsection{Stable Oxygen Isotopes $\left(\delta^{18} \mathrm{O}\right)$}

Oxygen isotope ratios of three consecutively sampled ontogenetic years in modern A. islandica specimen Ai24568 show three distinct sinusoidal patterns (summer peaks and winter troughs) with amplitudes of about $2 \%$ each (Fig. 4d). Assuming a constant modern $\delta^{18} \mathrm{O}_{\text {seawater }}$ ratio of $0 \%$ during shell formation, the measurements translate into water temperatures between 15 and $6{ }^{\circ} \mathrm{C}$ (Fig. $4 \mathrm{~d}$ ).

\section{Discussion and Conclusions}

When working on fossil shell material, the state of preservation must be evaluated prior to geochemical analysis (e.g., stable oxygen isotopes) to avoid serious errors and bias. Here, CRM represents a powerful, time-effective and non-destructive tool for the examination of shell carbonate polymorphs (Fig. 3).

In $A$. islandica shells it is possible to check the growth record for decadal variability throughout the life of the animal. In specimen AI-EgLo-02 (Lofoten, Norway) frequency analysis identified a significant 5-year signal, which, however, is not stationary over time (Fig. $4 a-c)$. Since the date of death is unknown, a direct correlation to observational or instrumental time-series is not feasible. This would, however, be an essential step to unambiguously link our 5-year signal to the NAO (cf., Wunsch 1999). A number of studies have shown indeed A. islandica shell growth patterns to correlate with known ocean-atmosphere oscillations such as NAO (Schöne et al. 2003a; Wanamaker et al. 2009). Nevertheless, further investigations of additional shell material as well as of local forcing mechanisms are required.

$\delta^{18} \mathrm{O}$ derived water temperatures $\left(6-15^{\circ} \mathrm{C}\right.$, Fig. $\left.4 \mathrm{~d}\right)$ in specimen Ai24568 correspond well to SST measurements $\left(2.8-13.7^{\circ} \mathrm{C}\right)$ for Troms $ø$, Norway. However, our temperature reconstruction does not account for seasonal changes in salinity

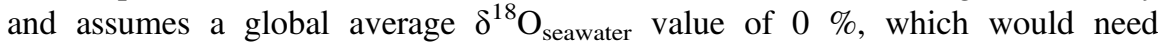
verification by on-site measurements. Further, an assumed growing season from February/March to September (Schöne et al. 2004) in A. islandica might explain truncated winter minimum temperatures. 
Conclusively, for demonstrating purposes, we combined the results from the frequency and $\delta^{18} \mathrm{O}$ analyses from two different shell specimens to give an exemplary perspective on the potential of A. islandica as a recorder of the environmental past. Accordingly, if $A$. islandica growth increment series can be synchronized with the external forcing signal (e.g., NAO) intra-annual analysis techniques (such as $\delta^{18} \mathrm{O}$ ) can be used to analyse whether intra-annual patterns differ between weak and strong phases of shell growth oscillation. In our example, $\delta^{18} \mathrm{O}$ analysis allowed to link a seasonal water temperature amplitude of about $9{ }^{\circ} \mathrm{C}$ to the most prominent phase of the 5-year periodic signal (Fig. 4c, d). The high temporal resolution combined with an exceptional longevity distinguish A. islandica shells from all other marine archives and show the great potential and uniqueness of $A$. islandica for climatic and environmental reconstructions on various time-scales.

Acknowledgments We would like to thank Salma Begum (AWI Bremerhaven), Carin Andersson Dahl (Bjerknes Centre for Climate Research, Uni Research), Lovísa Ásbjörnsdóttir (Icelandic Institute of Natural History) for providing the shell material. Further, Andreas Mackensen, Lisa Schönborn and Kerstin Beyer (all AWI Bremerhaven) are thanked for their help and advice with the stable oxygen isotope measurements.

\section{References}

Bathurst RGC (1964) The replacement of aragonite by calcite in the molluscan shell wall. In: Imbrie J, Newell NO (eds) Approaches to paleoecology. Wiley, New York, pp 357-376

Butler PG, Richardson CA, Scourse JD, Wanamaker AD Jr, Shammon TM, Bennell JD (2010) Marine climate in the Irish Sea: analysis of a 489-year marine master chronology derived from growth increments in the shell of the clam Arctica islandica. Quater Sci Rev 29:1614-1632

Butler PG, Wanamaker AD Jr, Scourse JD, Richardson CA, Reynolds DJ (2013) Variability of marine climate on the North Icelandic Shelf in a 1357-year proxy archive based on growth increments in the bivalve Arctica islandica. Palaeogeogr Palaeoclimatol Palaeoecol 373:141-151

Dahlgren TG, Weinberg JR, Halanych KM (2000) Phylogeography of the ocean quahog (Arctica islandica): influences of paleoclimate on genetic diversity and species range. Mar Biol 137:487-495

Dettman D, Lohmann KC (1995) Microsampling carbonates for stable isotope and minor element analysis: physical separation of samples on a 20 Micrometer scale. J Sediment Res 65A:566-569

Dettman DL, Reische AK, Lohmann KC (1999) Controls on the stable isotope composition of seasonal growth bands in aragonitic fresh-water bivalves (Unionidae). Geochim Cosmochim Acta 63:1049-1057

Grossman EL, Ku T-L (1986) Oxygen and carbon isotope fractionation in biogenic aragonite: temperature effects. Chem Geol 59:59-74

Hallmann N, Burchell M, Schöne BR, Irvine GV, Maxwell D (2009) High-resolution sclerochronological analysis of the bivalve mollusk Saxidomus gigantea from Alaska and British Columbia: techniques for revealing environmental archives and archaeological seasonality. J Archaeol Sci 36:2353-2364

Hendry JP, Ditchfield PW, Marshall JD (1995) Two-stage neomorphism of Jurassic aragonitic bivalves: implications for early diagenesis. J Sediment Res 65:214-224 
IPCC, Climate Change (2013) The physical science basis. Contribution of working group I to the 5th assessment report of the intergovernmental panel on climate change. Cambridge University Press, Cambridge

Ivany LC, Brey T, Huber M, Buick DP, Schöne BR (2011) El Niño in the Eocene greenhouse recorded by fossil bivalves and wood from Antarctica. Geophys Res Lett 38:L16709

Jones DS (1980) Annual cycle of shell growth increment formation in two continental shelf bivalves and its paleoecologic significance. Paleobiology 6:331-340

Maliva RG (1998) Skeletal aragonite neomorphism-quantitative modelling of a two-water diagenetic system. Sed Geol 121:179-190

Nehrke G, Poigner H, Wilhelms-Dick D, Brey T, Abele D (2012) Coexistence of three calcium carbonate polymorphs in the shell of the Antarctic clam Laternula elliptica. Geochem Geophys Geosyst 13:Q05014

Schöne BR (2013) Arctica islandica (Bivalvia): a unique paleoenvironmental archive of the northern North Atlantic Ocean. Global Planet Change 111:199-225

Schöne BR, Dunca E, Fiebig J, Pfeiffer M (2005a) Mutvei's solution: an ideal agent for resolving microgrowth structures of biogenic carbonates. Palaeogeogr Palaeoclimatol Palaeoecol 228:149-166

Schöne BR, Houk SD, Freyre Castro AD, Fiebig J, Oschmann W, Kroncke I, Dreyer W, Gosselck F (2005b) Daily growth rates in shells of Arctica islandica: assessing sub-seasonal environmental controls on a long-lived bivalve mollusk. Palaios 20:78-92

Schöne BR, Oschmann W, Rössler J, Castro ADF, Houk SD, Kröncke I, Dreyer W, Janssen R, Rumohr H, Dunca E (2003a) North Atlantic oscillation dynamics recorded in shells of a longlived bivalve mollusk. Geology 31:1037-1040

Schöne BR, Pfeiffer M, Pohlmann T, Siegismund F (2005c) A seasonally resolved bottom-water temperature record for the period AD 1866-2002 based on shells of Arctica islandica (Mollusca, North Sea). Int J Climatol 25:947-962

Schöne BR, Tanabe K, Dettman DL, Sato S (2003b) Environmental controls on shell growth rates and $\delta^{18} \mathrm{O}$ of the shallow-marine bivalve mollusk Phacosoma japonicum in Japan. Mar Biol 142:473-485

Schöne BR, Freyre Castro AD, Fiebig J, Houk SD, Oschmann W, Kröncke I (2004) Sea surface water temperatures over the period 1884-1983 reconstructed from oxygen isotope ratios of a bivalve mollusk shell (Arctica islandica, southern North Sea). Palaeogeogr Palaeoclimatol Palaeoecol 212:215-232

Torrence C, Compo GP (1998) A practical guide to wavelet analysis. Bull Am Meteorol Soc 79:61-78

Wanamaker A Jr, Kreutz K, Schöne B, Maasch K, Pershing A, Borns H, Introne D, Feindel S (2009) A late Holocene paleo-productivity record in the western Gulf of Maine, USA, inferred from growth histories of the long-lived ocean quahog (Arctica islandica). Int J Earth Sci 98:19-29

Weidman CR, Jones GA (1994) The long-lived mollusc Arctica islandica: a new paleoceanographic tool for the reconstruction of bottom temperatures for the continental shelves of the northern North Atlantic Ocean. J Geophys Res 99:18305-18314

Witbaard R, Franken R, Visser B (1997) Growth of juvenile Arctica islandica under experimental conditions. Helgolaender Meeresuntersuchungen 51:417-431

Wunsch C (1999) The interpretation of short climate records, with comments on the North Atlantic and Southern oscillations. Bull Am Meteorol Soc 80:245-255 